\title{
Critical Design Decisions in the Development of the Standard for Process Assessment
}

\author{
Terence P Rout \\ Software Quality Institute \\ Institute for Integrated and Intelligent Systems \\ Griffith University Queensland 4111 AUSTRALIA \\ T.Routegriffith.edu.au
}

\begin{abstract}
.
The development of an International Standard for Process Assessment commenced in 1993. Over the past 20 years, the standard suite has moved through three formal releases, and multiple drafts; during this time, several key design issues have been addressed, and in many cases reconsidered. This paper identifies key issues in the design of the Standard, and discusses decisions taken and their impact on the Standard, and on the theory and practice of process assessment.
\end{abstract}

Keywords. Process assessment; standardization; process improvement

\section{Introduction}

The technique of process assessment derives from the classical studies on process improvement of workers including Deming, Juran and Crosby; application of these concepts in studies such as reported by Radice [1] led to the development of the concepts of "model-based process improvement", and this evolved through the work of Humphrey [2] to the development of comprehensive models such as the CMM for Software [3]. The increasing popularity of this approach, and the increasing use of the technique by acquirers seeking to establish higher confidence in their suppliers, led to the establishment of a Study Group on the need for an International Standard addressing process assessment for software life cycle processes. The report of the Study Group [4] was accepted in 1992, leading to the initiation of work on the International Standard, ISO/IEC 15504.

The initial working drafts of the Standard documents were developed by the SPICE Project, and published in 1995; based on these drafts, the development of the first version of ISO/IEC 15504 (as a Technical Report, Type 2) proceeded, released in 1998. In 1999, work to restructure the TR as a full International Standard commenced, with publication of the first five parts over the period $2003-2008$. Since then, a further five parts of the Standard have been published; the current baseline is listed in Table 1. 


\begin{tabular}{|c|c|}
\hline Part 1 - Concepts and Vocabulary & Published (12 Nov 2004) \\
\hline Part 2 - Performing an assessment & Published (31 Oct 2003) \\
\hline $\begin{array}{l}\text { Part } 3 \text { - Guidance on performing an as- } \\
\text { sessment }\end{array}$ & Published (6 Jan 2004) \\
\hline $\begin{array}{l}\text { Part } 4 \text { - Guidance on use for process im- } \\
\text { provement and process capability deter- } \\
\text { mination }\end{array}$ & Published (2 Jul 2004) \\
\hline $\begin{array}{l}\text { Part } 5-\text { An exemplar Process Assess- } \\
\text { ment Model }-2^{\text {nd }} \text { Edition }\end{array}$ & Published (2012) \\
\hline $\begin{array}{l}\text { Part } 6 \text { - An exemplar system life cycle } \\
\text { process assessment model }-2^{\text {nd }} \text { Edition }\end{array}$ & $\begin{array}{l}\text { Approved for publication (2013); } \\
1^{\text {st Edition published (2010) }}\end{array}$ \\
\hline $\begin{array}{l}\text { Part } 7 \text { - Assessment of organizational } \\
\text { maturity }\end{array}$ & Published (25 Nov 2008) \\
\hline $\begin{array}{l}\text { Part } 8 \text { - An exemplar assessment model } \\
\text { for service management processes }\end{array}$ & Published (2012) \\
\hline Part 9 - Target process profiles & Published (2012) \\
\hline Part $10-$ Safety Extension & Published (2012) \\
\hline
\end{tabular}

Table 1 ISO/IEC 15504 - Current Status

At present, a major restructuring project is in progress, to redevelop the standard from a single, multi-part document to a set of related documents. In the course of this work, many of the design decisions taken over the course of development have been revisited; the purpose of this presentation is to summarise some of the critical decisions taken, and explore the rationale behind them.

\section{Key Design Issues}

Design issues evolved over the course of the development of the standard suite, and impacted most of the key aspects of the technique of process assessment. It is important to note that the level of theoretical understanding of process assessment has evolved along with the development of the Standards, with each driving the other. Key features of the domain, where critical decisions were debated, include the following.

\section{Domain Scope for the Standard}

The most obvious decision taken in relation to the Standard suite as a whole is the extension of scope, from a limited "Software Process Assessment" in the TR to the current scope of "Information technology - Process assessment". The decision was taken as part of the revision of the TR; while there was some discussion, it was seen as consistent with the overall extension in scope of the Standards Committee from "Software Engineering" to "Systems and Software Engineering"; it was also consistent with growing application of the technique of process assessment to other domains, in some cases well outside the field of Information Technology. Most recent- 
ly, the extension of scope to address IT Service Management is another important decision; this was driven essentially by the adoption of this domain into the scope of JTC1/SC7.

A further change in the scope of the Standard came with the development of Part 7 - Assessment of Organizational Maturity. The original Study Group report was very firm in rejecting an approach based on providing any "single number" result of assessment, providing for the definition of a profile of Process Capability. Over time, the link between defined Process Capability Profiles and Organizational Maturity was recognized, and the extension of scope became possible. It is also significant that as the Standard moved towards recognition of Maturity Levels, the CMMI explicitly recognized the Continuous Representation.

\section{Definition and Measurement of Processes}

The approach to defining and measuring (assessing) processes has changed substantially over the course of development, and with the evolution to the 330xx series is likely to change still more. The original Baseline Practices Guide, in the SPICE document set, defined its own architecture for software life cycle processes, and defined these processes in terms of sets of Base Practices, following the pattern of the Capability Maturity Model. This led to a considerable debate concerning the relationship between the architecture in the BPG, and that established in ISO/IEC 12207 Software Life Cycle Processes. The outcome was the establishment of the concept of the Process Reference Model, to serve as a repository of process definitions for a domain, and of the approach of defining processes in terms of purpose and outcomes.

The use of the Process Reference Model also opened the door to the broadening of scope of the Standard, referred to above. It made possible the adoption and development of additional process models, either as expansions to those currently available (e.g., Automotive SPICE [7]) or as an extension to new fields of interest (e.g. Enterprise SPICE [8] and the COBIT Assessment Model [9]).

In parallel with the adoption of the Reference Model concept came the development of the Measurement Framework for Process Capability, a meta-level framework that addressed many of the problems identified in the Baseline Practices Guide. In the BPG, while the definitions of the Capability Levels were clear, the distribution of components across the scale was uneven - Level 2 in the BPG contained 4 "common features" and a total of 12 "generic practices". In the revised Framework, levels from 2 to 5 all contained two "Process Attributes", which were the core elements in rating capability.

What appears to be the most significant decision taken over the 20 years of the development has been one of the most recent: the expansion of the technique of process assessment to cover process characteristics other than capability. This has resulted in the definition of a set of meta-level requirements for Measurement Frameworks, and has had a major impact on the terminology to be employed in the new Standard suite. It will be most interesting to see what the final impact of the decision will be. 


\section{Performing Assessment}

The definition of a clear meta-level framework for processes and process capability impacted in turn on the approach for assessing capability. The definition of the Measurement Framework drove a significant change in the ratings mechanism; in the SPICE documents, each Base Practice or Generic Practice was rated for adequacy, and an overall rating was derived from a formal combination of the individual practice ratings, based on equal weightings. The basic scale for rating "adequacy", however, was a four-point ordinal scale $(\mathrm{N}-\mathrm{P}-\mathrm{L}-\mathrm{F})$ which is still retained.

The approach resulted in the need for a very large number of individual ratings to be determined, and then weighted. The adoption of the Measurement Framework resulted in a much simpler approach with a significantly lower workload; two Process Attributes were rated at each Capability Level above 1.

The derivation of ratings was also impacted by decisions on the scope of the assessment. In the development of the SPICE Documents, the decision was that the scope of rating was to be the process instantiation, and this was retained through to the Preliminary Draft Technical Report ballot. At this stage, considerations of the difficulties encountered in consistent identification of instantiations led to the adoption of a requirement to rate Process Attributes across the whole scope of the assessment. The introduction of the concepts of assessment of organizational maturity, with the accompanying need for greater rigor in the conduct of the assessment, has led to the reintroduction of identification of instantiations.. This has had a significant impact on the redesign of the assessment framework, requiring definition of an agreed approach to aggregation of ratings and characterizations of process performance. The final impact of this on the rating approach is yet to be determined.

\section{Impact}

The design changes taken since the commencement of the standards development have been substantial, and have had a major impact on the development of the Standard, and also on its adoption and on the conduct of process assessment. It is noteworthy that many of the decisions were made with the support of empirical studies conducted through the SPICE Trials $[10,11]$, and that these investigations have generally supported the decisions taken.

The changes to the Standard have simplified the approach to exploring process capability, and have made the development of appropriate process models and tools simpler. The changes also opened up additional domains to the adoption of techniques of model-based improvement (through assessment) and benchmarking of organizational achievement.

It remains to be seen what the effect of the most recent changes will be; certainly we can be optimistic that they will result in the development of opportunities to understand the operations and characteristics of processes implemented in organizations more clearly. 


\section{References}

1. Radice, R.A., Harding, J.T., Munnis, P.E., Phillips, R.W., 1985. A Programming process study. IBM Systems Journal 24(2), 91-101.

2. Humphrey, W.S., Managing the Software Process. Reading, MA: AddisonWesley, 1989.

3. M. Paulk, B. Curtis, M.B Chrissis, and C.V. Weber, Capability Maturity Model for Software, Version 1.1. Technical Report CMU/SEI-93-TR-24, Software Engineering Institute, Pittsburgh, February 1993.

4. ISO/IEC JTC1/SC7, 1992. The Need and Requirements for a Software Process Assessment Standard, Study Report, Issue 2.0, JTC1/SC7 N944R, 11 June.

5. ISO/IEC TR 15504: 1998 - Information Technology - Software Process Assessment, Parts $1-9$.

6. ISO/IEC 15504: 2003 - 2012 - Information Technology - Process Assessment, Parts $1-10$.

7. Automotive, S. I. G. "Automotive SPICE Process Assessment Model." Final Release, 444 (2010): 46.

8. Enterprise SPICE. An enterprise integrated standards-base model (2008), http://www.enterprisespice.com/

9. ISACA (2011), COBIT Process Assessment Model (PAM), Using COBIT 4.1.

10. Ho-Won Jung, Robin Hunter, Dennis R. Goldenson and Khaled El-Emam, "Findings from Phase 2 of the SPICE Trials", Softw. Process Improve. Pract. 2001; 6: 205-242

11. Terence P. Rout \& Khaled El Emam \& Mario Fusani \& Dennis Goldenson \& Ho-Won Jung 2007, 'SPICE in retrospect: Developing a standard for process assessment', in Journal of Systems and Software, vol.80, no.9, Elsevier, Amsterdam. 